\title{
CUSTOS DE IMPLANTAÇÃO E MANUTENÇÃO DA ARBORIZAÇÃO DE RUAS DA CIDADE DE CURITIBA, PR ${ }^{1}$
}

\author{
Luciana Leal ${ }^{2}$, Daniela Biondi ${ }^{3}$, Roberto Rochadelli $^{3}$
}

\begin{abstract}
RESUMO - Este trabalho teve como objetivo compor os custos das árvores de rua em suas diferentes fases de desenvolvimento, considerando-se como estudo de caso a arborização viária da cidade de Curitiba, PR. O valor de uma árvore na idade " $n$ ” foi obtido pelo somatório dos custos das atividades de implantação e manutenção da arborização de ruas, considerando-se cinco centros de custos: produção de mudas, plantio e replantio, poda, remoção de árvores e planejamento e controle. Os custos tiveram de ser divididos em nove grupos de espécies formados de acordo com a taxa de crescimento em viveiro de espera e o porte. As espécies de maior custo foram aquelas com lento crescimento em viveiro e de grande porte. O método proposto mostrou-se aplicável aos órgãos municipais, podendo ser facilmente adaptado para outras cidades brasileiras.
\end{abstract}

Palavras-chave: Arborização urbana, produção de mudas, plantio, poda e remoção.

\section{THE IMPLANTATION AND MAINTENANCE COSTS OF URBAN STREET TREES IN CURITIBA, PR}

\begin{abstract}
The aim of this research was to obtain the urban street trees costs in its different phases of development, using the street tree program of Curitiba as a study case. The tree value at age $n$ was obtained by the sum of costs of tree implantation and maintenance, considering five cost centers: seedling production, planting and replanting, pruning, removal and planning and control. The costs were divided in nine species groups formed according to growing rate in the nursery and size. The species with the highest costs were those of slow growth rate in the nursery and large size. The valuation of a tree through its costs, which can be obtained at municipal institutions, is feasible and can be easily adapted to other Brazilian cities.
\end{abstract}

Keywords:Urban trees, seedling production, planting, pruning and removal.

\section{INTRODUÇÃO}

As árvores urbanas podem proporcionar vários benefícios ao ambiente urbano e à população, porém também proporcionam uma série de custos (NOWAK e CRANE, 2006).

Os custos das árvores de rua são relativos às atividades de implantação e manutenção do programa de arborização para determinado período de tempo, corrigidos monetária e financeiramente (GREY e DENEKE, 1986; DETZEL et al., 1998). Para compor esses custos podem ser consideradas as operações de plantio, nutrição, irrigação, tratamentos fitossanitários, podas de formação e limpeza, reparos às calçadas e meio-fio, queda de galhos sobre prédios, carros e até mesmo pedestres, folhas a serem varridas, entre outras (GREY e DENEKE, 1986; PHILLIPS, 1993).

\footnotetext{
${ }^{1}$ Recebido em 12.05.2007 e aceito para publicação em 19.05.2008.

${ }^{2}$ Programa de Pós-Graduação em Ciências Florestais da UFPR. E-mail:<luciana_paisagem @ yahoo.com.br> .

${ }^{3}$ Departamento de Ciências Florestais da Universidade Federal do Paraná (UFPR), Curitiba-PR. E-mail: <dbiondi@ufpr.br>.
} 
As informações sobre os custos relativos a uma árvore urbana devem ser de utilidade pública, porque a população precisa conhecer quanto custa, aos órgãos municipais, para se ter uma árvore plantada em determinado local.

Segundo Detzel et al. (1998), o volume de recursos aplicados pelas administrações municipais para o estabelecimento da arborização em ruas, parques e praças, quase sempre traduz a importância desse componente da infra-estrutura para os cidadãos. Especialmente com relação aquelas árvores situadas nas ruas, conhecer esses valores têm aplicação direta no planejamento das atividades relativas à implantação e manutenção da arborização e na otimização de recursos a ela destinados. A determinação de valores justiça-se também pela necessidade de aplicação de multas, indenizações e isenções estabelecidas segundo critérios de valoração de comprovadas eficácia e veracidade.

Trabalhos que abordem os custos da arborização urbana no Brasil são escassos. Um dos únicos trabalhos publicados foi realizado por Detzel et al. (1998), para a arborização de ruas da cidade de Maringá, PR.

Curitiba, capital do Estado do Paraná, conhecida por sua tradição na arborização urbana, com cerca de 300 mil árvores plantadas nas vias públicas, é uma das cidades brasileiras que carece de informações sobre os custos de suas árvores. Devido à necessidade de se estabelecer um método para compor esses custos, o objetivo desta pesquisa foi estabelecer as variáveis necessárias para compor os custos das árvores de rua em suas diferentes fases de desenvolvimento.

\section{MATERIAL E MÉTODOS}

Este estudo de caso foi realizado na arborização viária da cidade de Curitiba, PR, localizada na Região Sul do Brasil, na latitude $25^{\circ} 25^{\prime} 40^{\prime \prime}$ S e longitude $49^{\circ} 16^{\prime} 23^{\prime \prime} \mathrm{W}$, considerando-se as 22 espécies mais encontradas nas ruas da cidade, conforme Biondi e Althaus (2005).

Os dados para compor os custos de implantação e manutenção das árvores de rua em suas diferentes fases de desenvolvimento foram obtidos na Gerência de Arborização Pública do Departamento de Produção Vegetal da Secretaria Municipal de Meio Ambiente da Prefeitura Municipal de Curitiba, referentes a informações coletadas nos anos de 2005 e 2006. Para isso foram considerados cinco centros de custos, sendo estes: a) Produção de mudas - a propagação e a condução de mudas com tamanho padrão e características adequadas para arborização de ruas, segundo Gonçalves et al. (2004). A produção das mudas é feita nos seguintes viveiros: Horto Municipal da Barreirinha - área total de $80.000 \mathrm{~m}^{2}$, área construída de $904 \mathrm{~m}^{2}$ e produção de 15 mil mudas/ano em viveiro de semeadura e de 76.700 mudas em viveiro de espera; Viveiro Municipal Zoológico - área total de $16.000 \mathrm{~m}^{2}$ e área construída de 20 m²; Viveiro Parque Náutico - área total de 10.000 $\mathrm{m}^{2}$ e área construída de $55 \mathrm{~m}^{2}$ e Horto da Cidade Industrial de Curitiba - área total de $31.152 \mathrm{~m}^{2} \mathrm{e}$ área construída de $28 \mathrm{~m}^{2}$, que são utilizados como viveiros de espera, respectivamente para $7.251,7.851$ e 5.782 mudas. $\mathrm{Na}$ produção de mudas estão envolvidos diretamente 18 funcionários, sendo 14 deles no Horto da Barreirinha e quatro nos outros viveiros. Em todas as espécies, considerou-se o período de um ano como o tempo de permanência na fase de viveiro de semeadura. Para a definição do tempo de permanência das mudas em viveiro de espera, considerou-se o critério adotado por Cobalchini (1999), sendo: crescimento rápido espécies com permanência em viveiro de espera de até três anos após a repicagem; crescimento moderado - de três a quatro anos; e crescimento lento - de cinco anos ou mais.

b) Plantio e replantio nas vias públicas - considerando as operações das equipes de plantio, formada por um motorista e três ajudantes, com rendimento médio diário de 15 mudas, insumos (substrato, adubo, tutor de bambu e fitilho) e a prática de irrigação (cinco irrigações com caminhão-tanque até o pegamento das mudas). Para o replantio, considerou-se um índice médio de perdas de $65 \%$ devido a atos de vandalismo, conforme estimativas da Gerência de Arborização Pública.

c) Poda de árvores - consideraram-se as podas de manutenção, segurança, profilática e rebaixamento, de responsabilidade da Gerência de Arborização Pública, e a poda de árvores com interferência na fiação aérea realizadas pela Companhia Paranaense de Energia Copel. Também as operações para remoção de resíduos e de acompanhamento de equipe da Diretoria de Trânsito da Prefeitura de Curitiba - Diretran para a execução dos serviços, quando é necessária a interdição de uma rua devido a risco de queda de galhos sobre pedestres e veículos. Para as operações de poda da Gerência e de coleta de resíduos foram somente considerados os dados das equipes terceirizadas. A equipe de poda 
é composta por um motorista (líder) e três ajudantes (coletores), enquanto a equipe de coleta de resíduos é formada por um motorista e um ajudante. As equipes de poda tinham rendimento médio mensal de 170 árvores de pequeno porte (feito com veículo utilitário tipo Van), 270 árvores de médio porte (com caminhão médio ou semipesado, equipado com carroceria e cesto aéreo, com giro de $360^{\circ}$ ou infinito e alcance mínimo de 10 $m$ de altura) e de 680 árvores de grande porte (caminhão semipesado, equipado com carroceria e cesto aéreo, com giro de $360^{\circ}$ ou infinito e alcance mínimo de 20 $\mathrm{m}$ de altura). $\mathrm{O}$ número total estimado de árvores podadas pela Copel é de 65 mil árvores/ano. Cada equipe de poda é acompanhada por 0,77 equipes de coleta de resíduos, e cada três equipes de poda são acompanhadas por uma equipe da Diretran (formada por dois agentes).

d) Remoção de árvores - neste item, considerou-se a prática de remoção da parte aérea e tocos, incluindo também as operações de remoção de resíduos e de acompanhamento de equipe da Diretran. Nas operações de remoção da parte aérea foram considerados os mesmos rendimentos e custos por equipes das operações de poda, devido à não-existência de dados de rendimento estratificados entre tais operações. A remoção de tocos foi baseada no custo médio de aluguel de um destocador, devido a não existência de dados estratificados quanto ao porte das árvores.

e) Planejamento e controle da arborização de ruas relacionado às operações do setor administrativo da Gerência de Arborização Pública, em atendimento as 300 mil árvores estimadas nas ruas da cidade. Está localizada em área no Horto Municipal do Guabirotuba, no Bairro Guabirotuba. As construções (escritório, depósitos, sala de reuniões e almoxarifado) ocupam uma área de $1.100 \mathrm{~m}^{2}$.

Para cada operação dos respectivos centros de custos foram levantados os custos fixos, incluindo os juros sobre o capital investido em equipamentos, veículos e benfeitorias (considerando-se uma taxa de juros de $6 \%$ a.a.), a depreciação e manutenção de equipamentos e benfeitorias e os salários fixos; e os custos variáveis, como: aquisição de insumos (substratos, fertilizantes, adubos, defensivos e embalagens), material de consumo (escritório e campo) e despesas correntes com água, luz e telefone.

Para compor o capital investido em benfeitorias foi utilizado o custo unitário básico de construção (CUB), do mês de outubro de 2006, equivalente a $\mathrm{R} \$ 885,92 / \mathrm{m}^{2}$ (SINDUSCON-PR, 2006). Para os terrenos, o custo de uso da terra foi baseado nos valores obtidos por Leal (2007), que estimou esse custo para os bairros de Curitiba, por análise de regressão, como uma variável inversa à distância até o centro da cidade.

A manutenção ou conservação para equipamentos foi baseada nas informações de fornecedores/fabricantes e experiência de técnicos e, nas benfeitorias, considerouse que o custo para conservação ou reparo seria equivalente a $2 \%$ do seu valor inicial.

A depreciação foi calculada pelo método linear ou das cotas fixas, que a considera simplesmente como a desvalorização do bem, reduzindo gradualmente seu valor nos inventários sucessivos durante o período de utilização, conforme Silva et al. (2005). Nas construções em alvenaria, considerou-se uma vida útil de 20 anos, para equipamentos e veículos de 10 anos (DERAL-PR, 2006) e para ferramentas e utensílios de baixo custo de aquisição, de três anos (MATSUSHITA e SEPULCRI, 1999).

Os custos de poda de árvores de pequeno, médio e grande portes executados pela Copel tiveram como base os valores corrigidos quantificados por Seitz (1999). Já os custos de acompanhamento de equipe da Diretran se basearam nos valores fornecidos por esse departamento.

Os custos de produção de mudas foram estratificados de acordo com a taxa de crescimento em viveiro de espera (rápido, moderado ou lento) e conseqüente variação no tempo de permanência em viveiro. Já os custos de poda e remoção foram estratificados quanto ao porte das espécies (pequeno, médio e grande), devido aos diferentes equipamentos utilizados. Adotou-se que, na realização dessas podas, as árvores já teriam o tamanho adulto e seriam usados os equipamentos correspondentes ao seu porte. $\mathrm{O}$ período de ciclos de podas teve como base o número médio de árvores atendidas pelas equipes no período de um ano.

Com base nessa estratificação, os custos totais de uma árvore foram apresentados para nove grupos de espécies, denominados A - I, pela combinação da taxa de crescimento em viveiro de espera (rápido, moderado ou lento) e pelo porte (pequeno, médio e grande) (Quadro 1).

R. Árvore, Viçosa-MG, v.32, n.3, p.557-565, 2008 
Quadro 1 - Grupos de espécies de acordo com o porte e a taxa de crescimento em viveiro de espera Table 1 - Groups of species according to size and growth rate in the nursery

\begin{tabular}{|c|c|c|}
\hline \multicolumn{3}{|c|}{ GRUPOS } \\
\hline$\overline{\mathrm{A}}$ & $\bar{B}$ & $\bar{C}$ \\
\hline Pequeno porte & Pequeno porte & Pequeno porte \\
\hline Crescimento rápido em viveiro & Crescimento moderado em viveiro & Crescimento lento em viveiro \\
\hline $\mathrm{D}$ & $\mathrm{E}$ & F \\
\hline Médio porte & Médio porte & Médio porte \\
\hline Crescimento rápido em viveiro & Crescimento moderado em viveiro & Crescimento lento em viveiro \\
\hline $\mathrm{G}$ & $\mathrm{H}$ & I \\
\hline Grande porte & Grande porte & Grande porte \\
\hline Crescimento rápido em viveiro & Crescimento moderado em viveiro & Crescimento lento em viveiro \\
\hline
\end{tabular}

Os custos de uma árvore, apresentados para idades entre 1 e 30 anos (contabilizadas após o plantio) foram capitalizados a juros compostos de $6 \%$ a.a., conforme Silva et al. (2005). Os custos foram apresentados em Reais (R\$) e também em Dólares (US\$), conforme o câmbio do dia 22 de abril de 2008 (US $\$ 1,00$ $=\mathrm{R} \$ 1,658)$.

\section{RESULTADOS E DISCUSSÃO}

\subsection{Custos das atividades de implantação e manutenção das árvores de rua}

Os custos das operações de planejamento e controle da arborização de ruas, em atendimento às 300 mil árvores estimadas nas vias públicas da cidade de Curitiba, totalizaram R \$ 1,92/árvore/ano.

Na produção de mudas, o custo de uma muda de crescimento rápido em viveiro de espera, como a Koelreuteria paniculata totalizou $\mathrm{R} \$ 55,69$, enquanto uma muda de lento crescimento, com maior período de tempo em viveiro de espera, como a Tabebuia heptaphylla, foi de $\mathrm{R} \$ 88,43$ (Tabela 1). O maior tempo de permanência em viveiro de espera resulta no fato de que o custo de uma muda de lento crescimento seja 1,59 vez maior (ou $58,79 \%$ superior) a de uma muda de rápido crescimento. De acordo com Biondi e Althaus (2005), o custo das mudas para arborização de ruas é alto, principalmente pelo longo período de permanência em viveiro.

Os custos de produção de mudas observados nesta pesquisa são altos, e praticamente não se pode comparar com os viveiros comerciais. Numa instituição pública municipal, os viveiros têm objetivos diferentes de um particular, principalmente por ter como finalidade o lucro. Variáveis como o número de mudas produzidas, área total ocupada, número de funcionários e tempo de permanência das mudas no local fazem que o custo de mudas dos viveiros municipais seja maior do que a de um viveiro comercial.

O custo da operação de plantio de uma muda foi de $\mathrm{R} \$ 43,23$, acrescido do custo de produção de uma muda (Tabela 2). Porém, devido à perda de mudas implantadas decorrentes de atos de vandalismo, o custo de implantação de uma espécie de rápido crescimento, como Acer negundo, que inicialmente seria de $\mathrm{R} \$ 98,92$, passou a ser de $\mathrm{R} \$ 163,22$ (Tabela 3). O vandalismo não é um problema restrito à arborização da cidade de Curitiba. De acordo com Biondi (2000), está presente em quase todas as cidades do mundo, embora varie em proporções. Conforme Pauleit et al. (2002), em algumas cidades européias os danos por vandalismo afetam $30 \%$ dos plantios, segundo levantamento realizado entre 1999 e 2001.

O custo total da operação de poda realizada pela Gerência de Arborização Pública foi de R \$34,31/ árvore de pequeno porte e de R \$ 183,50/árvores de grande porte (ciclo de podas em intervalos de 12 em 12 anos), enquanto as operações de poda da Copel totalizaram $\mathrm{R} \$ 29,73$ /árvore de pequeno porte e R\$108,32/árvores de grande porte (cinco em cinco anos) (Tabela 4). Verifica-se que, no primeiro caso, o custo de poda de uma árvore de grande porte é 5,35 vezes maior ou $434,83 \%$ superior ao de árvores de grande porte.

McPherson e Simpson (2002), em estudo nas cidades de Santa Mônica e Modesto, Califórnia (EUA), verificaram que o custo por árvore podada foi de, respectivamente, US\$ 90,00 (ciclo de podas de um a três anos) e de US\$ 69,00 (ciclo de três a quatro anos). 
Tabela 1 - Custos de produção de mudas para a arborização de ruas da cidade de Curitiba Table 1 - Seedling costs for urban street trees in Curitiba

\begin{tabular}{|c|c|c|c|}
\hline \multirow{2}{*}{ Grupo } & \multirow{2}{*}{ Espécies } & \multicolumn{2}{|c|}{ Custos/Muda } \\
\hline & & $\mathrm{R} \$$ & US\$ \\
\hline $\begin{array}{l}\text { Rápido crescimento em viveiro } \\
(1+3 \text { anos })\end{array}$ & $\begin{array}{l}\text { Acer negundo } \mathrm{L} . \\
\text { Jacaranda mimosifolia } \mathrm{D} \text {. Don } \\
\text { Koelreuteria paniculata } \mathrm{Laxm} . \\
\text { Melia azedarach } \mathrm{L} . \\
\text { Tibouchina sellowiana } \text { Cogn. }\end{array}$ & 55,69 & 33,59 \\
\hline $\begin{array}{l}\text { Moderado crescimento em viveiro } \\
(1+4 \text { anos })\end{array}$ & $\begin{array}{l}\text { Anadenanthera colubrina (Vell.) Brenan } \\
\text { Bauhinia variegata } \mathrm{L} \text {. } \\
\text { Erythrina falcata Benth. } \\
\text { Lagerstroemia indica L. } \\
\text { Parapiptadenia rigida (Benth.) Brenan } \\
\text { Prunus serrulata } \text { Lindl. } \\
\text { Senna macranthera } \text { H. S. Irwin \& Barneby } \\
\text { Senna multijuga (Rich.) H. S. Irwin \& Barneby } \\
\text { Tipuana tipu (Benth.) Kuntze }\end{array}$ & 71,58 & 43,17 \\
\hline $\begin{array}{l}\text { Lento crescimento em viveiro } \\
(1+5 \text { anos })\end{array}$ & $\begin{array}{l}\text { Caesalpinia leiostachya (Benth.) Ducke } \\
\text { Cassia leptophylla } \text { Vogel } \\
\text { Lafoensia pacari A. St.-Hil. } \\
\text { Ligustrum lucidum Aiton } \\
\text { Magnolia grandiflora } \text { L. } \\
\text { Tabebuia alba (Cham.) Sandwith } \\
\text { Tabebuia chrysotricha (Mart. ex. A. DC.) Standl. } \\
\text { Tabebuia heptaphylla (Vell.) Toledo }\end{array}$ & 88,43 & 53,34 \\
\hline
\end{tabular}

Fonte: Os autores (2008).

Tabela 2 - Custos das operações de plantio para a arborização de ruas da cidade de Curitiba Table 2 - Planting costs of urban trees in Curitiba

\begin{tabular}{lrr}
\hline Operações & \multicolumn{2}{c}{ Custos/Muda } \\
\cline { 2 - 4 } & R \$ & US \$ \\
\hline Plantio & 38,94 & 23,49 \\
Irrigação & 4,29 & 2,59 \\
\hline TOTAL & 43,23 & 26,07 \\
\hline
\end{tabular}

Fonte: Os autores (2008).

Tabela 3 - Custos de implantação da arborização de ruas da cidade de Curitiba Table 3 - Implantation costs of urban trees in Curitiba

\begin{tabular}{|c|c|c|c|c|c|c|}
\hline \multirow{3}{*}{ Espécies } & \multicolumn{6}{|c|}{ Custos/Árvore } \\
\hline & \multicolumn{2}{|c|}{ Plantio } & \multicolumn{2}{|c|}{ Replantio } & \multicolumn{2}{|c|}{ Total } \\
\hline & $\mathrm{R} \$$ & US\$ & $\mathrm{R} \$$ & US\$ & $\mathrm{R} \$$ & US\$ \\
\hline Rápido crescimento em viveiro & 98,92 & 59,66 & 64,30 & 38,78 & 163,22 & 98,44 \\
\hline Moderado crescimento em viveiro & 112,23 & 67,69 & 72,95 & 44,00 & 185,18 & 111,69 \\
\hline Lento crescimento em viveiro & 131,66 & 79,41 & 85,59 & 51,62 & 217,24 & 131,02 \\
\hline
\end{tabular}

Fonte: Os autores (2008). 
Tabela 4 - Custos das operações de poda de árvores de rua na cidade de Curitiba Table 4 - Pruning costs of urban trees in Curitiba

\begin{tabular}{|c|c|c|c|c|c|c|c|c|}
\hline \multirow{3}{*}{ Espécies } & \multicolumn{8}{|c|}{ Custos/Árvore } \\
\hline & \multicolumn{2}{|c|}{ Poda Aérea } & \multicolumn{2}{|c|}{ Coleta de Resíduos } & \multicolumn{2}{|c|}{ Diretran } & \multicolumn{2}{|c|}{ Total } \\
\hline & $\mathrm{R} \$$ & US\$ & $\mathrm{R} \$$ & US\$ & $\mathrm{R} \$$ & US\$ & $\mathrm{R} \$$ & US\$ \\
\hline \multicolumn{9}{|c|}{ Gerência de Arborização } \\
\hline Pequeno porte & 15,04 & 9,07 & 15,06 & 9,08 & 4,21 & 2,54 & 34,31 & 20,69 \\
\hline Médio porte & 62,22 & 37,53 & 37,92 & 22,87 & 4,21 & 2,54 & 104,35 & 62,94 \\
\hline Grande porte & 119,06 & 71,81 & 62,23 & 37,53 & 4,21 & 2,54 & 183,50 & 110,68 \\
\hline \multicolumn{9}{|l|}{ COPEL } \\
\hline Pequeno porte & 10,46 & 6,31 & 15,06 & 9,08 & 4,21 & 2,54 & 29,73 & 17,93 \\
\hline Médio porte & 20,94 & 12,63 & 37,92 & 22,87 & 4,21 & 2,54 & 63,07 & 38,04 \\
\hline Grande porte & 41,88 & 25,26 & 62,23 & 37,53 & 4,21 & 2,54 & 108,32 & 65,33 \\
\hline
\end{tabular}

Fonte: Os autores (2008); valores corrigidos de SEITZ, 1999.

O ciclo das podas realizadas pela Gerência de Arborização Pública (12 em 12 anos) não representa um intervalo ideal para a obtenção de uma árvore com qualidade estética e fitossanitária, que, segundo Tattar (1978), seria a cada três anos. Já para redução de custos, Miller e Sylvester (1981) recomendam um intervalo ideal de ciclo de podas entre quatro e cinco anos, para a arborização da cidade de Milwaukee (EUA). Segundo esses últimos autores, o período do ciclo de poda tem significativo efeito sobre o custo total de uma árvore, sendo que longos ciclos de poda resultam em sua redução.

No Brasil, já foram realizados trabalhos por Santos (2000) e Velasco et al. (2006) de análises de técnicas para reduzir o número de podas e melhorar a convivência das árvores com a fiação elétrica, além da comparação dos custos de substituição das redes convencionais de energia por redes compactas e subterrâneas com os custos de poda.

Na remoção da parte aérea, os custos variaram de $\mathrm{R} \$ 15,04 / a ́ r v o r e$ de pequeno porte a $\mathrm{R} \$ 119,06$ / árvore de grande porte, enquanto para a remoção de tocos foi considerado o custo médio de remoção de $\mathrm{R} \$ 60,00$. O custo total de remoção (parte aérea e tocos) variou de $\mathrm{R} \$ 94,31$ para árvores de pequeno porte a $\mathrm{R} \$ 243,50$ para aquelas de grande porte (Tabela 5). Nas cidades de Modesto e Santa Mônica, Califórnia (EUA), os custos médios para remoção de uma árvore são ainda maiores, respectivamente de US\$264,00 e US\$396,00 (McPHERSON e SIMPSON, 2002).

\subsection{Custos totais de implantação e manutenção das árvores de rua}

Os custos estimados de uma árvore aos 30 anos variaram de $\mathrm{R} \$ 9.003,18$ (grupo A - espécies de crescimento rápido em viveiro e pequeno porte) a $\mathrm{R} \$ 18.913,96$ (grupo I - espécies de crescimento lento em viveiro e grande porte). Verificou-se que o custo total de uma árvore do grupo I é 2,10 vezes maior ou $110,08 \%$ superior ao de outra árvore do grupo A (Tabela 6).

Tabela 5 - Custos das operações de remoção de árvores de rua na cidade de Curitiba Table 5 - Removal costs of urban trees in Curitiba

\begin{tabular}{|c|c|c|c|c|c|c|c|c|c|c|}
\hline \multirow{3}{*}{ Porte } & \multicolumn{10}{|c|}{ Custos/Árvore } \\
\hline & \multicolumn{2}{|c|}{ Parte Aérea } & \multicolumn{2}{|c|}{ Tocos } & \multicolumn{2}{|c|}{ Diretran } & \multicolumn{2}{|c|}{ Coleta de Resíduos } & \multicolumn{2}{|c|}{ Total } \\
\hline & $\mathrm{R} \$$ & US\$ & $\mathrm{R} \$$ & US\$ & $\mathrm{R} \$$ & US\$ & $\mathrm{R} \$$ & US\$ & $\mathrm{R} \$$ & US\$ \\
\hline Pequeno & 15,04 & 9,07 & 60,00 & 36,19 & 4,21 & 2,54 & 15,06 & 9,08 & 94,31 & 56,88 \\
\hline Médio & 62,22 & 37,53 & 60,00 & 36,19 & 4,21 & 2,54 & 37,92 & 22,87 & 164,35 & 99,12 \\
\hline Grande & 119,06 & 71,81 & 60,00 & 36,19 & 4,21 & 2,54 & 62,23 & 37,53 & 243,50 & 146,86 \\
\hline
\end{tabular}

Fonte: Os autores (2008). 
Tabela 6 - Custos de implantação e manutenção da arborização de ruas da cidade de Curitiba Table 6 - Implantation and maintenance costs of urban trees in Curitiba

\begin{tabular}{|c|c|c|c|c|c|c|}
\hline \multirow{3}{*}{ Idade } & \multicolumn{6}{|c|}{ Custos de Implantação e Manutenção em R \$ e US\$ } \\
\hline & \multicolumn{2}{|c|}{$\begin{array}{c}\text { A (PP/CR) } \\
\text { Tibouchina sellowiana }\end{array}$} & \multicolumn{2}{|c|}{$\begin{array}{c}\text { B }(\mathrm{PP} / \mathrm{CM}) \\
\text { Bauhinia variegata } \\
\text { Lagerstroemia indica } \\
\text { Prunus serrulata } \\
\text { Senna macranthera } \\
\end{array}$} & \multicolumn{2}{|c|}{$\mathbf{C}(\mathrm{PP} / \mathrm{CL})$} \\
\hline & $\mathrm{R} \$$ & US\$ & $\mathrm{R} \$$ & US\$ & $\mathrm{R} \$$ & US\$ \\
\hline 1 & \multicolumn{2}{|r|}{165,87} & \multicolumn{2}{|r|}{179,91} & 332,28 & 200,41 \\
\hline 5 & 787,81 & 475,15 & 811,08 & 489,19 & 845,06 & 509,69 \\
\hline 10 & 1610,53 & 971,37 & 1633,81 & 985,41 & 1667,79 & 1005,90 \\
\hline 15 & 2780,57 & 1677,06 & 2803,84 & 1691,10 & 2837,82 & 1711,59 \\
\hline 20 & 4253,95 & 2565,71 & & 2579,75 & 4311,21 & 2600,24 \\
\hline 25 & 6364,58 & 3838,71 & 6387,86 & 3852,75 & 6421,84 & 3873,24 \\
\hline 30 & 9003,18 & 5430,15 & 9026,46 & 5444,18 & 9060,44 & 5464,68 \\
\hline IDADE & $\begin{array}{l}\text { D }(\mathrm{MP} \\
\text { Acerne }\end{array}$ & & $\begin{array}{r}\mathbf{E}(\mathrm{MP} / \\
\text { Lafoensia } \\
\text { Senna mu }\end{array}$ & & $\begin{array}{r}\mathbf{F}(\mathrm{MF} \\
\text { Cassia le } \\
\text { Ligustrum }\end{array}$ & llam \\
\hline & $\mathrm{R} \$$ & US\$ & $\mathrm{R} \$$ & US\$ & $\mathrm{R} \$$ & US\$ \\
\hline 1 & 349,26 & 210,65 & 372,53 & 224,69 & 406,52 & 245,19 \\
\hline 5 & 1250,93 & 754,48 & 1274,21 & 768,52 & 1308,19 & 789,02 \\
\hline 10 & 2693,43 & 1624,51 & 2716,70 & 1638,54 & 2750,69 & 1659,04 \\
\hline 15 & 4833,79 & 2915,43 & 4857,06 & 2929,47 & 4891,05 & 2949,97 \\
\hline 0 & 7417,08 & 4473,51 & 7440,36 & 4487,55 & 7474,34 & 4508,05 \\
\hline 25 & 11296,62 & 6813,40 & 11319,89 & 6827,44 & 11353,88 & 6847,93 \\
\hline 30 & 15922,91 & 9603,68 & 15946,18 & 9617,72 & 15980,16 & 9638,22 \\
\hline IDADE & $\begin{array}{r}\mathbf{G}(\mathrm{GP} \\
\text { Jacaranda } \\
\text { Koelreuteria } \\
\text { Melia aze }\end{array}$ & $\begin{array}{l}\text { ifolia } \\
\text { culata } \\
\text { ch }\end{array}$ & $\begin{array}{r}\mathbf{H}(\mathrm{GP} / \\
\text { Anadenanther } \\
\text { Erythrina } \\
\text { Parapiptade } \\
\text { Tipuana }\end{array}$ & $\begin{array}{l}\text { ubrina } \\
\text { ta } \\
\text { gida }\end{array}$ & $\begin{array}{r}\text { I }(\mathrm{GP} \\
\text { Caesalpinia } \\
\text { Magnolia g } \\
\text { Tabebuia h } \\
\text { T. alba,T. } \\
\end{array}$ & $\begin{array}{l}\text { achya } \\
\text { flora } \\
\text { hylla } \\
\text { tricha }\end{array}$ \\
\hline & $\mathrm{R} \$$ & US\$ & $\mathrm{R} \$$ & US\$ & $\mathrm{R} \$$ & US\$ \\
\hline 1 & 369,56 & 222,90 & 392,83 & 236,93 & 426,82 & 257,43 \\
\hline 5 & 1425,92 & 860,02 & 1449,19 & 874,06 & 1483,17 & 894,55 \\
\hline 10 & 3102,58 & 1871,28 & 3125,85 & 1885,31 & 3159,83 & 1905,81 \\
\hline 15 & 5715,57 & 3447,27 & 5738,84 & 3461,30 & 5772,83 & 3481,80 \\
\hline 20 & 8718,22 & 5258,27 & 8741,49 & 5272,31 & 8775,47 & 5292,81 \\
\hline 25 & 13497,42 & 8129,93 & 13502,69 & 8143,96 & 13536,67 & 8164,46 \\
\hline 30 & 18856,70 & 11373,16 & 18879,98 & 11387,20 & 18913,96 & 11407,70 \\
\hline
\end{tabular}

NOTA: $\mathrm{PP}=$ pequeno porte; $\mathrm{MP}=$ médio porte; $\mathrm{GP}=$ grande porte; $\mathrm{CR}=$ crescimento rápido em viveiro; $\quad \mathrm{CM}=$ crescimento moderado em viveiro; $\mathrm{CL}=$ crescimento lento em viveiro.

Fonte: Os autores (2008).

Ressalta-se que os custos da arborização de ruas de Curitiba poderiam ser ainda maiores, se as árvores recebessem todas as práticas de manutenção necessárias para manter o seu vigor, como: adubação, irrigação, tratamento de danos físicos e controle de pragas e doenças, recomendados por Grey e Deneke (1986), e também se fossem contabilizados outros custos, como reparos a calçadas e meio-fio, queda de galhos sobre prédios, carros ou pedestres e folhas a serem varridas, citados por Phillips (1993), como pontos negativos da arborização. Porém, as operações de poda e remoção correspondem às categorias de maior custo, conforme verificado em trabalhos de McPherson e Simpson (2002) e McPherson (2003), sendo representativos dos custos totais de uma árvore.

Entre as 22 espécies selecionadas para este estudo, nenhuma se encaixou no grupo $\mathrm{C}$, correspondente a 
espécies de crescimento lento em viveiro e pequeno porte. O maior número de espécies (cinco espécies) foi encontrado no grupo I (crescimento lento em viveiro e grande porte), justamente o grupo das árvores com maior custo de implantação e manutenção (Tabela 6).

Para a aplicação do método de composição de custos, é necessário conhecer a idade da árvore em avaliação. Esse é um fator limitante, segundo Detzel (1998), para obter com precisão o valor de uma árvore. Daí a importância do cadastramento da arborização urbana com registro de dados relativos a espécie, ano e local de plantio e, se possível, com registros computadorizados em banco de dados, como o proposto por Silva Filho et al. (2002) para a arborização de vias públicas da cidade de Jaboticabal, SP.

Os resultados apontaram os altos custos da arborização de ruas de Curitiba. Porém, considerando que os benefícios da arborização urbana excedem os seus custos, como mostrado em trabalhos de McPherson et al. (1999), McPherson e Simpson (2002) e Nowak et al. (2002), verificou-se o grande valor das $300 \mathrm{mil}$ árvores plantadas nas vias públicas da cidade. Portanto, a arborização de ruas é um patrimônio que deve ser mantido e conhecido pela população.

\section{CONCLUSÃO}

Pelo método proposto, os custos das árvores de rua da cidade de Curitiba variaram com a taxa de crescimento e o consequiente tempo de permanência das espécies em viveiro de espera; bem como os custos de poda e remoção, conforme o porte das espécies e diferentes equipamentos utilizados. Obviamente, as espécies de maior custo foram aquelas de grande porte e com lento crescimento em viveiro de espera.

A obtenção de dados sobre os custos de implantação e manutenção da arborização de ruas mostrou-se aplicável aos órgãos municipais, podendo o método proposto ser facilmente adaptado para outras cidades brasileiras. No entanto, para que esse método possa ser amplamente aplicado, principalmente em aspectos legais, é necessária a existência de um banco de dados com informações sobre as árvores a serem avaliadas e que os órgãos municipais possuam um programa de gerenciamento de custos para cada atividade da arborização de ruas.

R. Árvore, Viçosa-MG, v.32, n.3, p.557-565, 2008

\section{AGRADECIMENTOS}

Ao Departamento de Produção Vegetal da Secretaria Municipal de Meio Ambiente de Curitiba pelo fornecimento dos dados necessários à realização deste trabalho.

\section{REFERÊNCIAS}

BIONDI, D. Curso de arborização urbana. Curitiba: UFPR, 2000. 45p.

BIONDI, D.; ALTHAUS. M. Árvores de rua de Curitiba: cultivo e manejo. Curitiba: FUPEF, 2005. 182p.

COB ALCHINI, J. L. Considerações sobre as doze espécies florestais mais utilizadas na arborização de ruas de Curitiba/PR. Curitiba, 1999, 72f. Monografia (Especialização em Gerenciamento Ambiental na Indústria) - Universidade Federal do Paraná/ Centro de Tecnologia em Saneamento e Meio Ambiente - SENAI/CETSAM.

DETZEL, V. A.; MILANO, M. S.; HOEFLICH, V. A.; FIRKOWSKI, C. Desenvolvimento de um método de avaliação monetária de árvores urbanas e aplicação à situação de Maringá/PR. Floresta, Curitiba, v.28, n.1/2, p.31-49, 1998.

DERAL-PR - Departamento de Economia Rural do Estado do Paraná. Informações fornecidas pelo Departamento de Economia Rural, Curitiba / PR, 12 novembro 2006.

GONÇALVES, E. O.; PAIVA, H. N.; GONÇALVES, W.; JACOVINE, L. A. G. Avaliação qualitativa de mudas destinadas à arborização urbana no Estado de Minas Gerais. Revista Árvore, v.28, n.4, p.479-486, 2004.

GREY, G. W.; DENEKE, F. J. Urban Forestry . 2.ed. New York: John Wiley, 1986. 299p.

LEAL, L. Custos das árvores de rua Estudo de caso: cidade de Curitiba/ PR. Curitiba, 2007. 115f. Dissertação (Mestrado em Engenharia Florestal) - Setor de Ciências Agrárias, Universidade Federal do Paraná. 
MATSUSHITA, M. S.; SEPULCRI, O. Sistema renda rural: manual do usuário. Curitiba: EMATER - PR, 1999. 26p.

McPHERSON, E. G.; SIMPSON, J. R.; PEPER, P. J.; XIAO, Q. Benefit-cost analysis of Modesto's municipal urban forest. Journal of Arboriculture, v.25, n.5, p.235-248, 1999.

McPHERSON, E. G.; SIMPSON, G. R. A comparison of municipal forest benefits and costs in Modesto and Santa Monica. Urban

Forestry and Urban Greening, California, v.1, p.61-74, 2002.

McPHERSON, E. G. A benefit-cost analysis of ten street tree species in Modesto, California, U. S. Journal of Arboriculture, v.29, n.1, p.1-7, 2003.

MILLER, R. W.; SYLVESTER, W. A. An economic evaluation of the pruning cycle. Journal of Arboriculture, v.28, n.4, p.109-112, 1981.

NOWAK, D. J.; CRANE, D. E. Understanding the benefit and costs of Urban Forest Ecosystems. In: KUSER, J. E. Urban and Community Forestry in the Northeast. $2^{\text {nd }}$. New York: Springer, 2006. p.25-46.

NOWAK, D. J.; CRANE, D. E.; DWYER, J. F. Compensatory value of urban trees in the United States. Journal of Arboriculture, v.28, n.4, p.194-199, 2002.

PAULEIT, S.; JONES, N.; GARCIA-MARTINS, G.; GARCIA-VALDECANTOS, J. L.; RIVIERI, L. M.;VIDAL-BEAUDET, L.; BODSON, M.; RANDRUP, T. B. Tree stablishment practice in towns and cities: results from a European survey. Urban Forestry and Urban Greening, California, v.1, n.2, p.83-96, 2002.
PHILLIPS, L. E. Urban trees: a guide for selection, maintenance and master planning. New York: McGraw-Hill, 1993. 273p.

SANTOS, E. Avaliação quali-quantitativa da arborização e comparação econômica entre a poda e a substituição da rede de distribuição de energia elétrica da região administrativa centro-sul de Belo Horizonte/MG. Viçosa, 2000, 219f. Tese (Doutorado em Ciência Florestal) - Universidade Federal de Viçosa.

SEITZ, R. A. A planilha de custos de poda de árvores urbanas. In: ENCONTRO NACIONAL SOBRE ARBORIZAÇÃO URBANA, 8., 1999, Fortaleza. Anais... Fortaleza: SBAU, 1999. p.59.

SILVA FILHO, D. F.; PIZETTA, P. U. C.; ALMEIDA, J. B. S. A.; PIVETTA, K. F. L.; FERRAUDO, A. S. Banco de dados relacional para cadastro, avaliação e manejo da arborização em vias públicas. Revista Árvore, Viçosa, v.26, n.5, p.629-642, 2002.

SILVA, M. L.; JACOVINE, L. A. G.; VALVERDE, S. R. Economia Florestal. 2.ed. Viçosa: UFV, 2005. $178 \mathrm{p}$.

SINDUSCON - PR. Sindicato da indústria de construção civil no Estado do Paraná. CUB custo unitário básico. Disponível em: <http://www.sinduscon-pr.com.br> Acesso em: 04 setembro 2006.

TATTAR, T. A. Diseases of shade trees. New York: Academic Press, 1978. 361p.

VELASCO, G. D. N.; LIMA, A. M. L., COUTO, H. T. Z. Análise comparativa dos custos de diferentes redes de distribuição de energia elétrica no contexto da arborização urbana. Revista Árvore, Viçosa, v.30, n.4, p.679-686, 2006. 